\title{
História
}

\section{Entrevista com Silvia Maria Cintra da Silva}

\author{
Interview with Silvia Maria Cintra da Silva
}

\section{Entrevista con Silvia Maria Cintra da Silva}

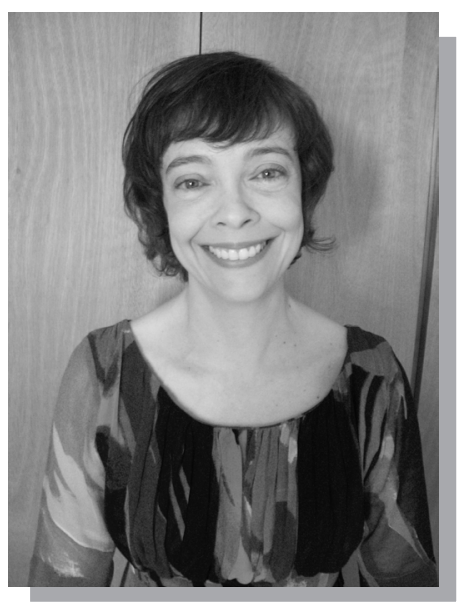

É graduada em Psicologia pela Pontifícia Universidade Católica de Campinas (1990), mestre em Educação pela Universidade Estadual de Campinas (1993) e doutora em Educação pela Universidade Estadual de Campinas (2002). Realizou pós-doutorado na USP, no Programa de Pós Graduação em Psicologia Escolar e do Desenvolvimento Humano (2007). Docente Associado III do Instituto de Psicologia da Universidade Federal de Uberlândia, ministra aulas na graduação e no mestrado e supervisiona estágio na área de Psicologia Escolar. Foi coordenadora do Curso de Graduação em Psicologia. Ocupa o cargo de Presidente Atual da Associação Brasileira de Psicologia Escolar e Educacional (ABRAPEE) desde setembro de 2014 e é Editora da Revista Psicologia Escolar e Educacional. Participa do GT de Psicologia e Políticas Educacionais da Associação Nacional de Pesquisa e PósGraduação em Psicologia - ANPEPP.

ENTREVISTADORA: Marilda Gonçalves Dias Facci

Marilda: Como ocorreu seu interesse pela área de Psicologia Escolar?

Silvia: Meu interesse explícito pela área começou durante a graduação, nas disciplinas Psicologia Escolar e Educacional (PEPA) 1 e 2, tanto pelo conteúdo como pelo entusiasmo das professoras, Ana Aragão e Luciana Castrillon, da PUC de Campinas (SP). Anteriormente, havia cursado Magistério no Ensino Médio, em Rio Claro (SP) e tomei contato com conteúdos ligados à Psicologia da Educação, que também me chamaram atenção. A Prof. ${ }^{a}$ Marie- ta R. Pereira Leite, que ao longo dos três anos do curso, ministrou diversas disciplinas, também é uma referência na área educativa. Constatei, posteriormente, que os estágios realizados durante a graduação também contribuíram para o meu interesse pelas questões educacionais.

Marilda: Como se deu sua formação profissional na área? Quais foram os seus principais interlocutores?

Silvia: Ainda na graduação, realizei dois estágios na área: um curricular, em uma creche municipal de Campinas, 
e outro extracurricular, em uma escola privada de Educação Infantil, na mesma cidade. Eu não sabia disso na época, mas tais experiências, bem como as respectivas supervisões de estágio, foram muito importantes para uma decisão posterior de escolher de modo definitivo a atuação em Psicologia Escolar. Fui supervisionada pela Prof. ${ }^{a}$ Maria Silvia P.M. L. Rocha, que também teve muita importância em minha formação, pela forma cuidadosa e instigante com que conduzia as supervisões e por seu olhar para a escola. Iniciei o Mestrado logo após a graduação, na Unicamp, sob orientação da Prof. ${ }^{a}$ Dra. Cecília Góes, tendo o privilégio de fazer parte de um grupo de pesquisa composto também pela Prof. ${ }^{a}$ Ana Luíza Smolka e pelo Prof. Angel Pino. Meus estudos acerca da Teoria Histórico-cultural datam dessa ocasião e influenciaram minha formação de modo decisivo. No final do mestrado, passei a trabalhar em uma instituição para crianças e adolescentes com deficiência, experiência fundamental para o exercício da profissão em nível institucional. Essa prática, que envolvia principalmente avaliação psicológica de crianças e formação continuada de professores, gerou-me uma necessidade imperiosa de aprofundar leituras em Psicologia da Aprendizagem e do Desenvolvimento em uma interlocução constante com os estudos do Mestrado. Lembro-me de que o conceito de Zona de Desenvolvimento Próximo (ZDP) foi imprescindível para eu compreender e intervir de modo diferenciado no processo avaliativo das crianças que chegavam à instituição com queixas de deficiência intelectual. A psicóloga com quem trabalhei, Márcia Toledo, foi uma grande parceira na organização e realização de projetos na instituição. O fato de nos respaldarmos em referenciais teóricos diferentes não foi um impeditivo para atuarmos e me ensinou que a parceria profissional pode se estabelecer de modo respeitoso e profícuo.

Ingressei na UFU em 1994, em um concurso na área de Psicologia Escolar e Educacional, para ministrar as disciplinas Psicologia Escolar e Problemas de Aprendizagem 1 no curso de Psicologia, e a disciplina Psicologia da Educação nos cursos de licenciatura. Inicialmente, organizei com colegas uma proposta de avaliação qualitativa de queixas escolares e atendimento de crianças com dificuldades no processo de escolarização, supervisionei estágios em escolas da rede pública de ensino de Uberlândia, trabalhei em projetos voltados para a formação continuada de professores. Desde 2004 desenvolvo um projeto de Psicologia Escolar no Ensino Superior por meio de um estágio na área focalizando os calouros do curso de Psicologia.

Meus grandes interlocutores têm sido meus colegas da UFU, de outras universidades e da ABRAPEE, além dos estudantes e estagiários. Considero o estágio supervisionado como um momento muito importante na formação do psicólogo e o fecundo encontro com os estagiários inevitavelmente nos instiga a (re)pensar nossa própria formação o tempo todo.

Marilda: Que temáticas você pesquisou na área?

Silvia: Em minha primeira pesquisa, no Mestrado, abordei a constituição social do desenho da criança; no
Doutorado, a importância da Arte para a formação do psicólogo escolar, sob a orientação da Prof. ${ }^{a}$ Célia Almeida. Em 2007, no estágio de pós-doutorado, realizado na USP com a Prof. ${ }^{a}$ Marilene Proença, tive a oportunidade de participar de um grande estudo interinstitucional, intitulado "A atuação do psicólogo na rede pública de Educação frente à demanda escolar: concepções práticas e inovações ${ }^{1 "}$. Essa experiência, ao longo de quatro anos, permitiu-me tanto uma aprendizagem em relação à pesquisa propriamente dita, nas dimensões qualitativa e quantitativa, como gerou a publicação do livro "Atuação do psicólogo na Educação Básica: concepções, práticas e desafios” pela EDUFU, em 2014. Em seguida, compus outra equipe de pesquisa, também interinstitucional ${ }^{2}$, no estudo "A formação do psicólogo escolar e as Diretrizes Curriculares em Psicologia: concepções teóricas, bases metodológicas e atuação profissional", que teve como objetivo principal analisar a formação dada aos futuros psicólogos nos Cursos de Graduação em Psicologia quanto à ênfase nos processos educativos, tendo em vista as Diretrizes. Atualmente coordeno a pesquisa "Atuação do Psicólogo Escolar no Ensino Superior - concepções teóricas e possibilidades de atuação ${ }^{3 \prime}$, que pretende mapear, conhecer e analisar a atuação do psicólogo no Ensino Superior no estado de Minas Gerais, buscando compreender em que medida esta se aproxima das discussões mais recentes da área de Psicologia Escolar e Educacional. De modo geral, são temáticas voltadas para a formação e a atuação do psicólogo escolar. É importante mencionar que as pesquisas que oriento no Mestrado em Psicologia e em projetos de Iniciação Científica também abraçam esse escopo, que envolve a medicalização, além da interlocução com a Arte.

Marilda: Que experiências você menciona como mais significativas no campo da Psicologia Escolar e que influenciaram e influenciam a sua prática profissional?

Silvia: Como canta Gonzaguinha, "Toda pessoa sempre é as marcas / Das lições diárias de outras tantas pessoas" e, neste sentido, eu talvez nem consiga, no espaço desta entrevista, mencionar todas as experiências, mas uma muito significativa foi a vivenciada na instituição para crianças e adolescentes com deficiência, em que me deparei com a necessidade de estudar mais para poder atuar de modo mais efetivo. As supervisões com Adriana Lech Cantuária, em Campinas, foram essenciais para pensar sobre o trabalho e a instituição e, posteriormente,decidir-me a prestar o concurso para docente na UFU. As investigações realizadas na pósgraduação, as aulas e o contato com outros pesquisadores também foram fundamentais para minha constituição como docente e pesquisadora. Tomei tanto gosto pelo universo da

1 Nos respectivos estados, a pesquisa foi coordenada por Marilda Gonçalves Dias Facci (Paraná), Lygia de Sousa Viégas (Bahia), Celso Francisco Tondin (Santa Catarina), Iracema Neno Cecílio Tada (Acre e Rondônia) e Silvia Maria Cintra da Silva (Minas Gerais).

2 A pesquisa foi realizada nos Estados de São Paulo, Minas Gerais, Goiás e Rondônia.

3 As três pesquisas foram financiadas pela FAPEMIG. 
pesquisa que ministro uma disciplina sobre pesquisa qualitativa no Programa de Mestrado da UFU desde 2003...

Marilda: Do seu ponto de vista, quais seriam as principais questões a serem enfrentadas ainda pela Psicologia Escolar e Educacional?

Silvia: Há questões que ainda são recorrentes - e antigas - como o fracasso escolar e os modos de compreensão e intervenção sobre este fenômeno, que comporta outra importante discussão sobre a avaliação psicológica e o olhar mais ampliado do psicólogo sobre o processo de escolarização, a escola, as políticas públicas etc. Outro ponto delicado e complexo é a medicalização do espaço escolar, que tem mudado de roupagem, com rótulos que se alternam na eleição de um problema orgânico localizado na criança. Outro campo a ser enfrentado é o Ensino Superior, seara que ainda conta com poucos estudos e que tem se mostrado terreno fértil para o trabalho do psicólogo escolar.

Marilda: Como iniciou sua participação na ABRAPEE?

Silvia: Iniciei minha participação como associada e, em 2004, junto à Diretoria com o convite feito pela Prof. ${ }^{a}$ Eulália Henriques Maimone, para compor, como Primeira Secretária, a chapa que ela encabeçava. É muito diferente a participação nessas duas posições; creio que somente após integrar a Diretoria pude ter mais clareza sobre a importância de uma entidade como a ABRAPEE. Sou muito grata à Eulália por este convite, que me abriu as portas para a Psicologia Escolar e Educacional de um modo incomensurável.

Marilda: Na atualidade, quais são as ações desenvolvidas pela ABRAPEE?

Silvia: AABRAPEE tem organizado o principal evento de Psicologia Escolar e Educacional no país, o CONPE, que neste ano realizará sua $12^{\mathrm{a}}$ edição, em São Paulo. As cinco Representações Estaduais (Minas Gerais, Paraná, Rondônia, Goiás e São Paulo) também realizam seus encontros regionais, com um número expressivo de participantes. Além disto, a entidade tem se engajado em muitas frentes, como o acompanhamento do Projeto de Lei 3688/2000, que determina que a rede pública de educação básica conte com serviços de Psicologia e de Serviço Social para atender às prioridades definidas pelas políticas educacionais e apresença ativa no Fórum Sobre Medicalização da Educação e da Sociedade. É importante citar o apoio a manifestos, como o de repúdio à adoção e à institucionalização de uma avaliação em larga escala de habilidades de crianças em aspectos não cognitivos e socioemocionais, anunciada em
2014, no Fórum Internacional de Políticas Públicas "Educar para as Competências do Século 21". Com assento no Grupo de Trabalho da Resolução sobre Ética em Pesquisa nas Ciências Humanas e Sociais (CHS), a ABRAPEE também apoiou a Carta Aberta de Resposta à "Carta da CONEP ao Grupo de Trabalho da Resolução sobre Ética em Pesquisa nas Ciências Humanas e Sociais (CHS)" no início de 2015. Na cidade de São Paulo, a entidade esteve presente à Reunião do Fórum Municipal de Educação da Cidade de São Paulo, na qual se discutiu o Plano Nacional de Educação (PNE) e a interface deste com os âmbitos municipais e estaduais. A manutenção e gestão desta Revista é uma importante ação desenvolvida pela ABRAPEE, que preza pelo atendimento de seu escopo, ou seja, a publicação de manuscritos relativos à atuação, formação e história da Psicologia no campo educacional, textos de reflexão crítica sobre a produção acadêmico-científica e relatos de pesquisas na área,assim como na sua interface com a Educação. Cito, ainda, a participação, a convite do Ministério da Educação, nas Audiências Públicas em Brasília sobre a Psicopedagogia e a Psicologia no Ensino Médio. Também a convite do Ministério, a ABRAPEE compõe o grupo que está finalizando uma grande pesquisa sobre a violência na escola. Como se pode constatar, são muitas e importantes ações.

Marilda: Fazendo parte da diretoria da ABRAPEE, que desafios você considera que estão postos para a Associação?

Silvia: Inicialmente, os desafios que estão colocados para a Educação de modo geral: a qualidade de ensino no país e a valorização do trabalho docente, que considero diretamente ligados ao PL 3688/2000. Neste sentido, a garantia de editais específicos para a contratação de psicólogos na rede pública é um ponto fundamental. A questão da formação do psicólogo para trabalhar no campo educativo também é um aspecto a ser destacado, tanto no que se refere à formação inicial, durante a graduação, como à continuada. Destaco ainda - e o item anterior está relacionado a isto -anecessidade da luta permanente contra a medicalização da educação, que tem trazido consequências nefastas para nossas crianças e adolescentes.

Marilda: Na sua avaliação, qual é o impacto da ABRAPEE desde a sua criação até o presente momento?

Silvia: Um impacto muito grande! Se considerarmos as ações em que a entidade está engajada, e são demandas postas pela própria sociedade ao longo da história da entidade, temos conseguido, de modo coerente, entrar em muitas frentes que são caras à Psicologia Escolar e Educacional. 
Silvia Maria Cintra da Silva (silvia_ufu@hotmail.com) - Universidade Federal de Uberlândia.

Marilda Gonçalves Dias Facci (marildafacci@gmail.com) - Universidade Estadual de Maringá.

Presidente Anterior da ABRAPEE, professora do Departamento e Programa de Pós-Graduação em Psicologia da Universidade Estadual de Maringá. 